\title{
СМЫСЛООБРАЗУЮЩАЯ ДЕЯТЕЛЬНОСТЬ УЧАЩИХСЯ КАК УСЛОВИЕ ЭФФЕКТИВНОГО РАЗВИТИЯ ЛИЧНОСТИ И МОТИВАЦИИ НА ЗАНЯТИЯХ ПО АНГЛИЙСКОМУ ЯЗЫКУ
}

\section{Жданько Анна Павловна}

Автор статьи исходит из предположения, что смыслообразующая деятельность студентов на занятиях по английскому языку - это мощный инструмент развития мотивации и личности. B статье мы доказываем то, что движущей силой смыслообразования является обмен иенностями педагога и его учащихся. Раскрывается сущность механизмов воздействия на смысловую сферу студентов. Показан алгоритм кодирования смысловой сферы учащихся, приводящий к определенной модели поведения. Первый этап кодирования заключается в поиске дополнительных мотивов. На втором этапе выбирается словесно-визуальный образ для установления личностносмысловых связей. Также в статье подчеркивается важность интегрированного английского, что повышает значимость изучения иностранного языка, профильного предмета и приводит к образованию новых смыслов. В этом случае устанавливается взаимосвязь личностных смыслов и содержания образования. Благодаря этому содержание образования инициирует развитие студентов и повышает их успеваемость. В статье описаны методы, которые мы использовали для активизации смыслообразования. Мы применяли метод эвристического прогнозирования, аналитический метод, метод «мозгового итурма». Метод эвристического прогнозирования позволяет предвидеть события посредством анализа прошлого и настоящего опыта. Аналитический метод позволяет выявлять взаимосвязь объекта и факторов, влияющих на него. Метод «мозгового штурма» позволяет получить большое количество продуктивных идей. В статье описаны особенности психологического развития возрастной группы респондентов, учет которых способствует достижению цели исследования. В статье мы доказали большую значимость смыслообразующей деятельности студентов для их личностного развития.

Ключевые слова: личность, развитие, смыслообразование, личностные смыслы, смыслообразующие связи, мотивация, психологические особенности, уроки английского, воздействие, смысловая сфера. 
По справедливому мнению многих психологов и педагогов, содержание учебного процесса должно быть насыщено личностно значимыми смыслами, т. е. представлять интерес, ценность для самих учащихся. Личностно-смысловой характер содержания учебной деятельности успешно решает проблемы эффективного усвоения знаний, развития личности, формирования положительного отношения к учебному предмету $[1,16]$. Необходимо установить смысловые связи между личным опытом учащихся и учебным материалом для того, чтобы изучаемый материал стал значимым для учащихся и был усвоен.

Так, например, в ходе работы над творческим проектом по английскому языку по теме «Leisure» («Досуг») были установлены смысловые связи между личным опытом учащихся и учебным материалом по теме, что усилило интерес учащихся к изучаемой теме, позволило раскрыть творческий потенциал учащихся, более глубоко усвоить учебный материал, выявить интересы и ценности учащихся. Творческий проект выявил разносторонний характер интересов учащихся. Студенты с удовольствием обсуждали свои увлечения, их пользу и значение в своей жизни. Положительные эмоции способствовали смыслообразующей деятельности учащихся, ведь смыслу присуща пристрастность [9].

Ценностные приоритеты человека раскрывают многие мотивы и цели его жизнедеятельности. Знание ценностей учащихся позволяет эффективно корректировать и развивать личность студентов. Смысл обучения - в обмене ценностями [3]. Регуляция смыслообразования учащихся может осуществляться с применением механизмов смыслотехнического воздействия. У Д. А. Леонтьева подробно описаны механизмы смыслотехнического воздействия [11]. Так, например, если у учащихся слабая мотивация к изучению иностранного языка, мы разработали и применяем следующую смыслотехническую схему для повышения мотивации:

1. Подключаем дополнительные мотивы изучения иностранного языка (знание английского пригодится при трудоустройстве, мотив соревнования, изучение английского в интеграции с профилем и т. д.).

2. Выбираем точный словесно-визуальный образ для установления смысловых связей. Например, на студентов, обучающихся по направлению «автомобилестроение», оказывают воздействие следующие образы: перспективная работа для специалистов со знанием английского на совместных предприятиях «Nissan Motor Company». Данная схема проходит кодирование и превращается в факты поведения [10].

На занятиях по иностранному языку, если иностранный язык не является профилем, смыслообразующей деятельности учащихся способствует интеграция иностранного языка в профильные дисциплины. Например, достаточно эффективно изучение иностранного языка на основе автомобилестроения, экономики, 
менеджмента. Иностранный язык начинает в такой ситуации работать на профиль, помогая студентам осознать реальную значимость материала [2].

Вот пример интегрированного занятия по английскому языку на основе автомобилестроения. На занятии применялись технологии личностносмыслового развития учащихся. Тема занятия: «The Car of the Future» («Автомобиль будущего»). Занятие было направлено на реализацию следующих задач: развитие мотивации учащихся; развитие критического мышления учащихся; творческую самореализацию учащихся; развитие навыков иноязычной коммуникативной компетенции; закрепление лексико-грамматического материала по разделу «Устройство автомобиля».

Учащиеся выполняли проектную работу поэтапно:

1. What will be the car fuel of the future? (Какое топливо для автомобилей будет использоваться в будущем?)

2. Find out the pros and cons about gasoline, diesel, hydrogen, electric power (Выделите плюсы и минусы бензина, дизельного топлива, водорода, электрической энергии).

3. Complete your results with fuel options chart (Дополните ваши результаты информацией из таблицы 1).

Таблица 1.

\section{Pros and Cons of Fuels}

\begin{tabular}{|c|c|c|c|c|c|c|c|}
\hline \multicolumn{2}{|c|}{ gasoline } & \multicolumn{2}{|c|}{ diesel } & \multicolumn{2}{|c|}{ hydrogen } & \multicolumn{2}{|c|}{ electric power } \\
\hline pros & cons & pros & cons & pros & cons & pros & cons \\
\hline $\begin{array}{c}\text { ac- } \\
\text { cesible }\end{array}$ & $\begin{array}{l}\text { expen- } \\
\text { sive }\end{array}$ & $\begin{array}{c}\text { produ- } \\
\text { ces less } \\
\text { CO }\end{array}$ & $\begin{array}{l}\text { NOx ox- } \\
\text { ides of } \\
\text { nitrogen } \\
\text { are bed }\end{array}$ & $\begin{array}{c}\text { no } \\
\text { pollution }\end{array}$ & $\begin{array}{l}\text { highly } \\
\text { explo- } \\
\text { sive }\end{array}$ & $\begin{array}{l}\text { lower permile } \\
\text { fuel costs }\end{array}$ & $\begin{array}{c}\text { costs more } \\
\text { than equiv- } \\
\text { alent gas } \\
\text { cars }\end{array}$ \\
\hline $\begin{array}{c}\text { easy to } \\
\text { buy }\end{array}$ & $\begin{array}{l}\text { less } \\
\text { efficient }\end{array}$ & $\begin{array}{c}\text { cheaper } \\
\text { than } \\
\text { gas }\end{array}$ & & $\begin{array}{c}\text { superior } \\
\text { fuel }\end{array}$ & $\begin{array}{l}\text { expen- } \\
\text { sive } \\
\text { techno- } \\
\text { logy }\end{array}$ & $\begin{array}{l}\text { lower mainte- } \\
\text { nance costs }\end{array}$ & $\begin{array}{l}\text { added cost } \\
\text { of in-home } \\
\text { charge }\end{array}$ \\
\hline & polluter & $\begin{array}{l}\text { clean } \\
\text { diesel } \\
\text { or biod- } \\
\text { iesel }\end{array}$ & & no smell & $\begin{array}{l}\text { diffi- } \\
\text { cult to } \\
\text { collect }\end{array}$ & $\begin{array}{c}\text { powertrain is } \\
\text { under warran- } \\
\text { ty for longer } \\
\text { than most gas } \\
\text { engines }\end{array}$ & $\begin{array}{l}\text { typical } \\
\text { range of } \\
\text { only } 75 \text { to } \\
100 \text { miles }\end{array}$ \\
\hline & smells & $\begin{array}{c}\text { gas } \\
\text { stations } \\
\text { exist }\end{array}$ & & $\begin{array}{l}\text { inex- } \\
\text { pensive } \\
\text { material }\end{array}$ & $\begin{array}{l}\text { new } \\
\text { engine } \\
\text { /car }\end{array}$ & $\begin{array}{l}\text { can be more } \\
\text { fun to drive } \\
\text { than gas cars } \\
\text { because elec- } \\
\text { tric power has } \\
\text { continuous } \\
\text { torque }\end{array}$ & $\begin{array}{l}\text { popularity } \\
\text { has made } \\
\text { availability } \\
\text { of public } \\
\text { charging } \\
\text { stations a } \\
\text { challenge in } \\
\text { some areas }\end{array}$ \\
\hline & & efficient & & plentiful & & & \\
\hline & & & & efficient & & & \\
\hline
\end{tabular}


4. What will the car of the future look like? (Как будет выглядеть машина будущего?)

Вышеперечисленные задания студенты выполняли вначале индивидуально, затем в ходе групповой дискуссии учащиеся дополняли свои выводы, находили новые решения. Задания носили проблемно-творческий характер и были направлены на развитие критического мышления. Задания развивают навыки прогнозирования, так необходимые для жизни в 21 в.

Прогнозирование - это способность предвидеть какие-либо явления, посредством анализа прошлого и настоящего опыта. При прогнозировании мы использовали аналитический метод, метод «коллективной генерации идей», метод эвристического прогнозирования [19]. У каждого из вышеперечисленных методов есть свои преимущества.

Аналитический метод позволяет выявить взаимосвязь объекта прогнозирования и факторов, влияющих на него. Так, при проектировании автомобиля будущего, учащиеся учитывали распространенность того или иного вида топлива, его стоимость, его влияние на экологию, затраты на создание нового двигателя и частей автомобиля при условии использования нового вида топлива, внешний вид кузова в зависимости от скорости автомобиля, состояния дорог и т. д.

Метод «коллективной генерации идей», или метод «мозгового штурма» позволяет обработать индивидуальные независимые идеи и получить большое количество новых продуктивных идей $[14,20]$. В ходе «мозгового штурма» была получена как общеизвестная информация, так и новые ценные идеи. К достоинствам метода «мозгового штурма» также можно отнести наличие комфортного психологического климата, способствующего активизации воображения, генерированию идей [15].

Суть метода эвристического прогнозирования заключается в построении и дальнейшем усечении «дерева поиска» [12]. Достоинством данного метода является то, что он может применяться для прогнозирования любых явлений, независимо от их природы и уровня знаний о предмете исследования.

Таким образом, задачи развития критического мышления, мотивации, самореализации учащихся были успешно осуществлены с помощью технологии личностно-смыслового развития, где мыслительная деятельность студентов была источником развития учащихся $[5,18]$. Приведем еще один пример занятия по английскому языку со студентами первого курса с применением технологии личностно-смыслового развития. Тема занятия: «People's Character and Personality» («Характер людей и личность»). Занятие было направлено на реализацию следующих задач: развитие навыков самоанализа учащихся; развитие критического мышления учащихся; развитие мотивации учащихся; 
корректировка развития личности учащихся; тренировка и закрепление лексико-грамматического материала по теме.

Занятие было составлено с учетом возрастных психолого-педагогических особенностей развития студентов. Студенты относятся к юношескому возрастному периоду. В этом возрасте проявляется большая избирательность к учебным предметам, вызванная желанием получить хорошую профессию [7]. Юноши и девушки продолжают открывать в себе какие-то новые качества. По нашему мнению, задача преподавателя - помочь студентам открыть и развить в себе положительные качества. Также у молодых людей возникает острая потребность в эмоциональном контакте, общении.

Первое задание на занятии было направлено на саморефлексию и развитие навыков перевода. Задания, направленные на саморефлексию, способствуют становлению и развитию смысловой сферы, т. е. смыслообразованию [8]. Студентам было предложено перевести и пройти англоязычный тест, выявляющий тип личности - идентификатор типов Майерс-Бриггс. Студенты прошли тестирование на английском языке. Далее учащиеся проанализировали результаты тестирования, которые были представлены в виде аутентичных англоязычных текстов. Анализ включал в себя выявление своих сильных и слабых сторон, и с учетом этого прогнозирование способов корректировки своего поведения, мировоззрения, с целью достижения благополучия в личной и профессиональной сфере. Иными словами, студенты активно извлекали смыслы из предложенного материала $[11,13]$. Также присутствовал момент смыслотворчества, когда учащиеся открывали для себя новые смыслы. С занятия студенты ушли с установкой на дальнейший поиск решений поставленной проблемы, что, по мнению многих ученых, способствует более успешному достижению целей и задач занятия [6].

Таким образом, смыслообразующая деятельность учащихся на занятиях по английскому языку способствовала личностно-смысловому развитию учащихся, развитию мотивации, реализации принципов межпредметной интеграции, диалогового, рефлексивного, текстосозидающего обучения.

\section{Литература}

1. Абакумова И. В., Ермаков П. Н., Фоменко В. Т. Новодидактика. Книга 1. Методология и технологии обучения: в поисках развивающего ресурса. - М.: КРЕДО, 2013. - 162 с.

2. Абакумова И. В., Ермаков П. Н., Фоменко В. Т. Новодидактика. Книга 2. Образовательные технологии: новые ракурсы. - М.: КРЕДО, 2013. - 122 с.

3. Абакумова И. В., Ермаков П. Н., Фоменко В. Т. Новодидактика. Книга 3. От классической дидактики - к дидактической инноватике. - М.: КРЕДО, 2013. - 134 c. 
4. Абакумова И. В., Ермаков П. Н., Фоменко В. Т. Новодидактика. Книга 4. Структурная дидактика как направление современной педагогики. М.: КРЕДО, 2013. - 152 с.

5. Абакумова И. В. Обучение и смысл: смыслообразование в учебном процессе. - Ростов н/Д: Изд-во Рост. ун-та, 2003. - 480 с.

6. Асмолов А. Г. По ту сторону сознания: методологические проблемы неклассической психологии. - М.: Смысл, 2002. - 480 с.

7. Донцов Д., Сенкевич Л. Психологические особенности, социальнопсихологические закономерности и специфика развития личности в юношеском возрасте // Российский научный журнал. - 2013. - № 1 (32). С. 198-207.

8. Ермаков П. Н., Лабунская В. А. Психология личности. - М.: Эксмо, 2007. $656 \mathrm{c}$.

9. Леонтьев А. Н. Деятельность. Сознание. Личность. - М.: Смысл, Академия, 2005. - 352 с.

10. Леонтьев А. А. Основы психолингвистики. - М.: Смысл, 1997. - 287 с.

11. Леонтьев Д. А. Психология смысла: природа, строение и динамика смысловой реальности. 2-е, испр. изд. - М.: Смысл, 2003. - 487 с.

12. Amabile T. M., Barsade S. G., Mueller J. S., Staw B. M. Affect and creativity at work // Administrative Science Quarterly. - 2005. - Vol. 50. - no. 3. pp. 367-403.

13. Amabile T. M., Hennessey B. A. Creativity // Annual Review of Psychology. 2010. - no. 61. - pp. 569-598.

14. Boroditsky L. Does Language Shape Thought?: Mandarin and English Speakers' Conceptions of Time // Cognitive Psychology. - 2001. - no. 43. - pp. 1-22.

15. Browne M. N., Keely S. M. Asking the right questions: A guide to critical thinking. - Upper Saddle River, NJ: Pearson Prentice-Hall, 2009. - 212 p.

16. Cameron J., Banko K. M., Pierce W. D. The pervasive negative effects of rewards on intrinsic motivation: The myth continues //The Behavior Analyst. - 2001. Vol. 24. - no. 1. - pp. 1-44.

17. Cattell R. B. Personality structure and the new fifth edition of the 16 PF // Educational and Psychological Measurement. - 1995. - Vol. 55. pp. 926-937.

18. Chomsky N. Language and mind. - New York: Cambridge University Press, 2006. - 209 p.

19. Collins A. M., Loftus E. F. A spreading-activation theory of semantic processing // Psychological Review. - 1975. - Vol. 82. - no. 6. - pp. 407-428.

20. Zhang L. Does student-teacher thinking style match/mismatch matter in students' achievement? // Educational psychology. - 2006. - Vol. 26. no. 3. - pp. 395-409. 